\title{
Pembuatan Aplikasi Permainan Pengenalan Provinsi di Indonesia Melalui Game "Adventure Indonesia" Berbasis Android
}

\author{
Yusuf Ashari $^{1)}$, Rinta Kridalukmana ${ }^{2)}$, Ike Pertiwi Windasari ${ }^{2)}$ \\ Jurusan Sistem Komputer, Fakultas Teknik, Universitas Diponegoro \\ Jl. Prof. Sudharto, Tembalang, Semarang, Indonesia
}

\begin{abstract}
Indonesia adalah Negara yang luas dan kaya akan keanekaragaman aspek keruangan. Secara administratif menurut UU RI Nomor 20 Tahun 2012 Indonesia tentang pembentukan provinsi Kalimantan Utara yang menjadikan Indonesia terdiri dari 34 Provinsi. Hal ini berdampak terhadap aspek kehidupan terutama pada aspek pendidikan. Pada tingkat sekolah dasar siswa telah diajarkan untuk mengenal wilayah Indonesia. untuk mempermudah siswa sekolah dasar dalam memahami dan mengenal provinsi dibutuhkan suatu aplikasi edukasi yang dapat mengenalkan karakteristik dan nama ibukota dari provinsi di Indonesia oleh karena itu muncul sebuah ide untuk merancang dan membangun aplikasi permainan “Adventure Indonesia” ini diharapkan menjadi sarana permainan tentang pengenalan provinsi di Indonesia.

Aplikasi permainan 'Adventure Indonesia' dibuat menggunakan perangkat lunak Unity versi 5 . Pengembangan multimedia yang digunakan adalah Multimedia Development Life Cycle (MDLC) yang memiliki enam tahap, yaitu tahap konsep (Concept), tahap perancangan (Design), tahap pengumpulan materi (Material Collecting), tahap pembuatan (Assembly), tahap pengujian (testing), dan tahap distribusi (Distribution). Pengujian black-box juga digunakan pada aplikasi ini.

Hasil dari penelitian adalah berupa aplikasi permainan "Adventure Indonesia" yang dapat berjalan pada perangkat berbasis android. Aplikasi ini berisi pengenalan karakteristik dan ibukota dari provinsi di Indonesia. Berdasarkan pengujian dengan menggunakan metode black-box, seluruh fungsi yang ada dalam aplikasi permainan telah berhasil dan berjalan sesuai dengan fungsinya masing-masing.
\end{abstract}

Kata kunci : Android, unity, Adventure Indonesia, Permainan, MDLC

\section{PENDAhUluAN}

I ndonesia merupakan Negara yang luas dan kaya akan keragaman aspek keruangan. Menurut data terbaru dari Badan Informasi Geospacial (BIG), Indonesia memiliki 13.466 pulau. Di antara jajaran pulau tersebut, terdapat lima pulau terbesar seperti : Pulau Irian Jaya (Papua), Pulau Kalimantan, Pulau Sumatera, Pulau Jawa, dan Pulau Sulawesi. Selain pulau tersebut, masih ada kelompok pulau lain yang memiliki luas wilayah yang lebih kecil, seperti Kepulauan Nusa Tenggara serta Kepulauan Maluku. ${ }^{[1]}$

Secara administratif menurut UU RI Nomor 20 TAHUN 2012 tentang pembentukan Provinsi Kalimantan Utara membuat Provinsi yang ada di Indonesia menjadi berjumlah 34 Provinsi.perubahan tersebut berdampak terhadap berbagai aspek kehidupan, baik aspek sosial, budaya, ekonomi maupun politik. Termasuk pada aspek pendidikan, terjadi perubahan kurikulum yang membuat buku - buku pelajaran edisi lama hanya menjadi arsip.

Pada tingkat Sekolah Dasar siswa telah diajarkan untuk mengenal wilayah Indonesia. Pendidikan geografi tentu sudah termasuk dalam kurikulum kelas VI Sekolah Dasar, yaitu materi tentang pengenalan wilayah Indonesia yang dimasukkan dalam mata pelajaran Ilmu Pengetahuan Sosial (IPS) ${ }^{[2]}$. Untuk mempermudah siswa SD khususnya siswa kelas VI dalam memahami dan menghafal peta provinsi beserta ibukotanya tanpa harus membuka peta Indonesia, dibutuhkan suatu media pembelajaran yang efektif dan efisien. Media pembelajaran yang sesuai dengan segmentasi anak-anak adalah suatu permainan edukatif (game education), karena game lebih mudah diterima anak-anak dibandingkan dengan metode konvensional seperti penggunaan buku.

Permainan atau game merupakan format multimedia yang biasa digunakan oleh guru dalam pembelajaran khususnya untuk anak-anak. Permainan adalah salah satu produk teknologi yang dapat digunakan sebagai alternatif media pembelajaran dan mengingat materi belajar ${ }^{[3]}$. Hal inilah yang dimanfaatkan penyusun untuk mengembangkan suatu game education yang mengajak anak bermain serta belajar mengenali provinsi serta karakteristik masingmasing provinsi yang ada di Indonesia. Sehingga anakanak lebih mudah dalam memahami gambaran peta Indonesia, letak tiap provinsi, nama provinsi beserta ibukota provinsi yang ada di Indonesia.

Dengan mengangkat judul tugas akhir pembuatan aplikasi permainan pengenalan provinsi di Indonesia melalui Game 'Adventure Indonesia' berbasis android diharapkan dapat mengenali peta provinsi serta ibukota masing- masing provinsi yang ada di Indonesia.

Untuk menghindari pembahasan yang meluas maka dalam tugas akhir ini ditetapkan batasan-batasan masalah dengan hal-hal sebagai berikut:

a. Aplikasi permainan ini hanya akan membahas tentang pemetaan dan pengenalan nama 34 provinsi beserta nama ibukota setiap provinsi yang ada di Indonesia.

b. Aplikasi permainan ini bekerja dengan konsep adventure game yang mengharuskan pengguna menghadapi bermacam halangan, dan harus 
memecahkan puzzle agar dapat melanjutkan ke tingkat berikutnya.

c. Aplikasi ini dibuat menggunakan perangkat lunak Unity, dengan bahasa pemrograman C\#, dan berbasis dua dimensi.

d. Aplikasi berjalan pada smartphone dengan sistem operasi Android versi 4.4.2 (KitKat) serta versi diatasnya.

e. Aplikasi permainan ini hanya dapat dimainkan oleh satu pemain saja (single player).

f. Aplikasi ini tidak dapat terhubung dengan koneksi Internet atau bersifat Game Offline.

\section{LANDASAN TEORI}

\section{A. Penelitian Terdahulu}

Penelitian ini didasari oleh penelitian yang sebelumnya perah dilakukan yaitu pada game yang berjudul "Peta Buta Indonesia" yang di buat oleh Victor Anggriawan, Alvian Agustinus Tandiputra, dan David. Pada permainan tersebut, pengguna disajikan menu belajar dan menu permainan. Dimana pada menu belajar terdapat peta buta Indonesia yang terdapat 33 tombol, dimana setiap tombol mewakili 33 provinsi yang ada pada peta buta Indonesia yang berisikan informasi setiap provinsi. Sedangkan pada menu latihan terdapat 3 macam bentuk soal, yaitu soal tipe 1, soal tipe 2 dan soal tipe 3 . Soal tipe 1 hanya berisi pertanyaan seputar nama provinsi yang ada di Indonesia, soal tipe 2 berisikan seputar nama, laut, selat danau, gunung dan pulau yang berada di Indonesia, dan pada soal 3 berisikan pertanyaan seputar provinsi yang dipilih oleh pengguna ${ }^{[4]}$.

\section{B. Permainan (Game)}

Game berasal dari kata bahasa inggris yang memiliki arti dasar permainan. Permainan dalam hal ini merujuk pada pengertian "kelincahan intelektual". permainan juga bisa diartikan sebagai arena keputusan atau aksi pemainnya. Ada target-target atau tujuan yang ingin dicapai seorang pemain. Kelincahan Intelektual, pada tingkat tertentu, merupakan ukuran sejauh mana permainan itu menarik untuk dimainkan secara maksimal ${ }^{[5]}$.

Berdasarkan pada perangkat yang digunakan, permainan dapat dibedakan menjadi beberapa jenis yaitu $^{[6]}$.

a. Personal Computer $(P C)$, merupakan game yang dibuat untuk komputer baik berbasis menggunakan sistem operasi Windows, Mac, maupun Linux

b. Console game, merupakan perangkat keras yang dibuat oleh pihak ketiga seperti Sony, Microsoft, dan Nintendo.

c. Mobile platform, merupakan permainan yang terdiri atas sesuatu yang bisa dibawa kemanamana atau disebut portable.

\section{Android}

Android merupakan sistem operasi untuk telepon seluler yang berbasiskan Linux. Android menyediakan platform terbuka bagi para pengembang untuk menciptakan aplikasi mereka sendiri sehingga dapat digunakan oleh bermacam peranti penggerak. Pemrograman Android membutuhkan Android SDK (Software Development Kit) dan juga Java Development Kit. Setelah itu dibutuhkan Java IDE yang digunakan untuk menuliskan coding Android. Salah satu tools yang dapat digunakan dalam pemrograman Android adalah Eclipse Helios karena Eclipse sangat mendukung proses penulisan code Android dan menjadikan proses development Android menjadi lebih mudah $^{[7]}$.

\section{Multimedia}

Pengertian multimedia menurut Rosch : "Multimedia adalah kombinasi dari komputer dan video" atau menurut McCormick : "Multimedia secara umum merupakan kombinasi tiga elemen yaitu suara, gambar dan teks". Jadi dapat disimpulkan bahwa multimedia merupakan kombinasi teks, seni, suara, gambar, animasi dan video yang disampaikan dengan komputer atau peralatan manipulasi elektronik dan dapat disampaikan dan/atau dikontrol secara interaktif [8].

\section{E. Metodologi Pengembangan Multimedia}

Metodologi yang digunakan adalah Multimedia Development Life Cycle (MDLC) yang bersumber dari Luther dan sudah dimodifikasi oleh Sutopo. Metodologi pengembangan multimedia tersebut terdiri dari enam tahap, yaitu konsep (concept), desain (design), pengumpulan materi (material collecting), pembuatan (assembly), pengujian (testing), dan distribusi (distribution). Keenam tahap ini tidak harus berurutan dalam prakteknya, tahap-tahap tersebut dapat saling bertukar posisi. Meskipun begitu, tahap konsep memang harus menjadi hal yang pertama kali dikerjakan ${ }^{[9]}$.

MDLC ditunjukkan pada Gambar 1 berikut

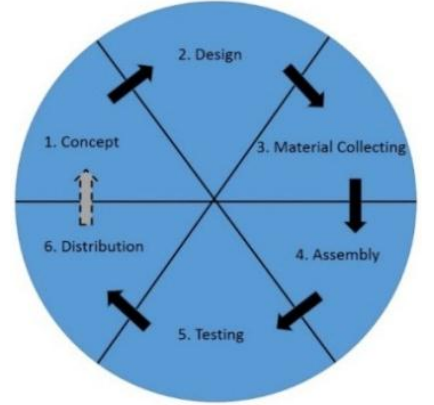

Gambar 1. Tahapan pengembangan multimedia.

1. Konsep adalah tahap untuk menentukan tujuan dan siapa pengguna (identifikasi audiensi).

2. Desain adalah tahap pembuatan spesifikasi mengenai arsitektur program, gaya, tampilan, dan kebutuhan material/bahan untuk program.

3. Pengumpulan Materi adalah tahap pengumpulan bahan yang sesuai dengan kebutuhan yang dikerjakan. 
4. Pembuatan adalah tahap pembuatan semua objek atau bahan multimedia. Pembuaatan aplikasi didasarkan pada tahap design, seperti storyboard, bagan alir, dan/atau struktur navigasi.

5. Tahap pengujian dilakukan setelah menyelesaikan tahap pembuatan dengan menjalankan aplikasi/program dan melihat hasilnya apakah ada kesalahan atau tidak.

6. Distribusi merupakan tahap aplikasi akan disimpan dalam suatu media penyimpanan. Jika media penyimpanan tidak cukup untuk menampung aplikasinya, maka kompresi terhadap aplikasi tersebut akan dilakukan. Tahap ini juga dapat disebut tahap evaluasi untuk pengembangan produk yang sudah jadi supaya menjadi lebih baik. Hasil evaluasi ini dapat digunakan sebagai masukan untuk tahap konsep pada produk selanjutnya ${ }^{[10]}$.

\section{F. Unity $3 D$}

Unity merupakan mesin permainan atau alat pembuat permainan yang memungkinkan orang-orang kreatif membangun video game. Dengan menggunakan Unity, pengguna dapat membangun video game lebih cepat dan mudah dari sebelumnya ${ }^{[11]}$.

Dalam Unity disediakan berbagai pilihan bahasa pemrograman untuk mengembangkan permainan, antara lain JavaScript, C\#, dan BooScript. Namun meskipun disediakan tiga bahasa pemrograman, kebanyakan pengembang menggunakan JavaScript dan C\# sebagai bahasa yang digunakan untuk mengembangkan permainan. Unity juga mendukung pembuatan permainan dalam berbagai platform, misal Unity Web, Windows, Mac, Android, iOS, XBox, Playstation 3 dan Wii.

\section{A. Konsep}

\section{PERANCANGAN SiSTEM}

Permainan ini dapat dimainkan oleh semua kalangan masyarakat. Permainan ini dirancang dengan perpaduan antara teks, suara dan gambar dalam desain permainan. Adapun skenario dari permainan "Adventure Indonesia" adalah sebagai berikut:

1. Permainan "Adventure Indonesia" terdiri atas 8 halaman yaitu halaman utama, halaman loading, halaman materi, halaman stage 1, halaman Puzzle1, halaman stage 2, halaman puzzle 2, halaman stage 3, halaman puzzle 3.

2. Misi permainan ini adalah pengguna mengumpulkan potongan puzzle pada setiap stage. Setelah misi pengumpulan potongan puzzle selesai, pengguna diminta untuk menyusun potongan puzzle tersebut dengan waktu yang telah ditentukan. Selain itu, pengguna juga harus menghindari setiap rintangan yang ada di dalam permainan pada saat misi pengumpulan potongan puzzle.
3. Permainan ini memiliki 3 tingkat permainan yaitu tingkat mudah Sumatra, tingkat sedang Jawa Kalimantan , dan tingkat susah Sulawesi Maluku Nusatenggara Papua. Masing-masing tingkatan memiliki kesulitan berbeda. Pada tingkat mudah jumlah potongan puzzle yang dikumpulkan sejumlah 10 potong, pada tingkat sedang sejumlah 11 potong, dan pada tingkat susah sejumlah 13 potong.

4. Aturan dalam permainan ini adalah pada misi pengumpulan puzzle, pemain harus menghindari setiap obstacle yang datang. Energi pemain akan berkurang jika menabrak obstacle. Jika energi pemain habis maka permainan berakhir.

\section{B. Desain atau Perancangan}

Dalam tahap perancangan ini dibagi menjadi tiga yaitu merancang spesifikasi kebutuhan aplikasi, pembuatan rancangan permainan menggunakan use case dan sequence diagram dan merancang desain tampilan permainan melalui storyboard.

1. Spesifikasi Kebutuhan Aplikasi

Aplikasi permainan "Adventure Indonesia" menggunakan beberapa perangkat lunak dalam pembuatannya. Spesifikasi perangkat yang digunakan adalah sebagai berikut:

a. Microsoft Windows 7 Ultimate

Sistem operasi ber-platform windows yang digunakan untuk membuat dan mengembangkan permainan ini.

b. Unity 5.0

Merupakan tool yang digunakan untuk membuat dan mengolah permainan ini. Pada aplikasi "Adventure Indonesia", diprogram menggunakan bahasa pemrograman $\mathrm{C \#}$.

c. CorelDraw X5 Portable

Perangkat lunak yang berguna untuk merancang grafis.

d. Visual Paradigm versi 12.2

Merupakan aplikasi perangkat lunak pembuat use case, dan sequence diagram.

\section{Perancangan dengan Use Case Diagram}

Permainan 'Adventure Indonesia' memiliki satu pemakai yaitu user sebagai pengguna permainan ini. User dapat berinteraksi dan dapat melakukan tindakan ke dalam sistem yang sudah memiliki skenario di dalamnya. Berikut merupakan use case diagram dari permainan 'Adventure Indonesia' yang telah digambarkan pada Gambar 2. 


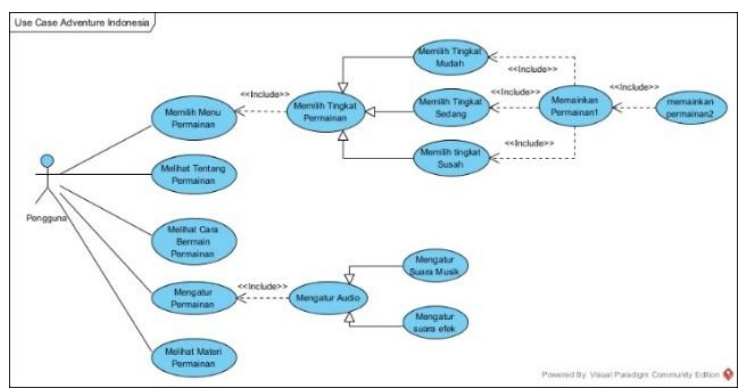

Gambar 2. Use Case diagram permainan

\section{Perancangan dengan sequence diagram}

Berikut merupakan sequence diagram memainkan permainan1 yang ditunjukkan pada Gambar 3.

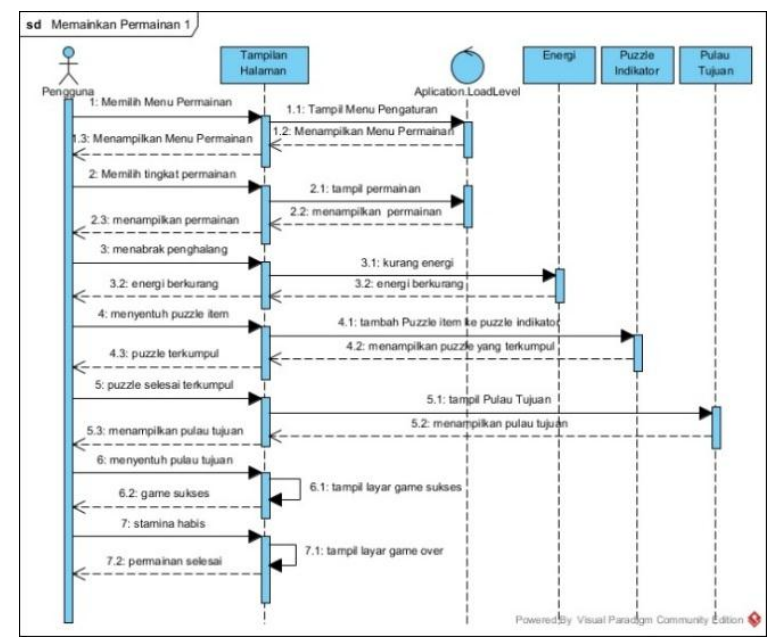

Gambar 3. Sequence Diagram Memainkan Permainan1

Berikut adalah sequence diagram memainkan permainan2 yang ditunjukkan pada Gambar 4.

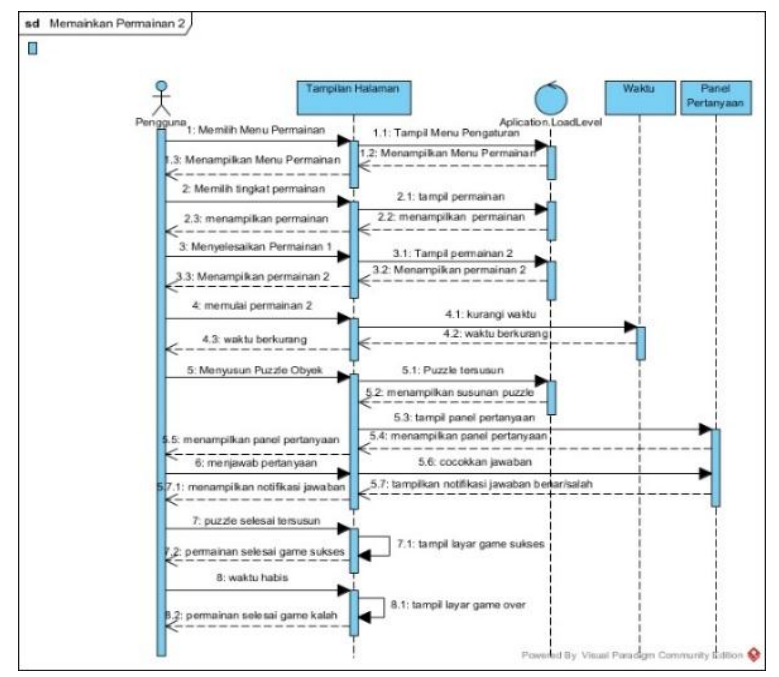

Gambar 4. Sequence Diagram Memainkan Permainan2

\section{Perancangan Permainan dengan Storyboard}

Pada desain tampilan permainan akan dirancang desain berupa tampilan gambar beserta tombol-tombol yang ada pada halaman permainan "Adventure
Indonesia" sesuai dengan fungsinya masing-masing. Tampilan rancangan halaman utama ditunjukkan pada Gambar 6.

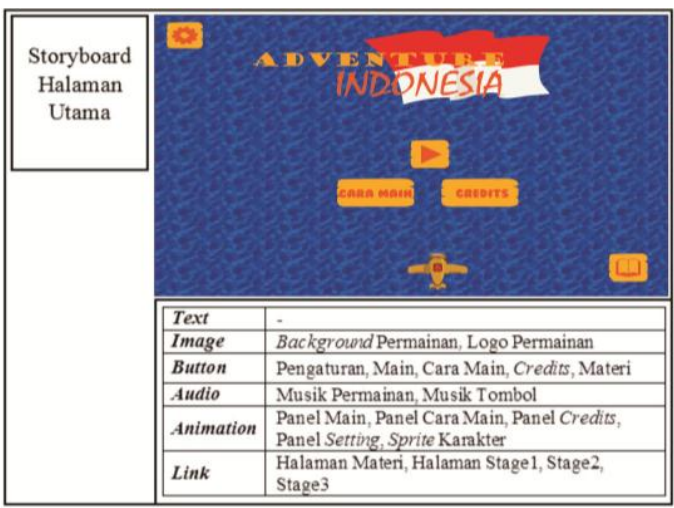

Gambar 6. Tampilan Storyboard Halaman Utama

Tampilan rancangan Permainan1 ditunjukkan pada Gambar 7. Tampilan halaman ini terdiri teks, gambar, audio, dan animasi. Selain itu terdapat tombol menu yang berisi panel pause yang digunakan untuk menghentikan permainan sementara.

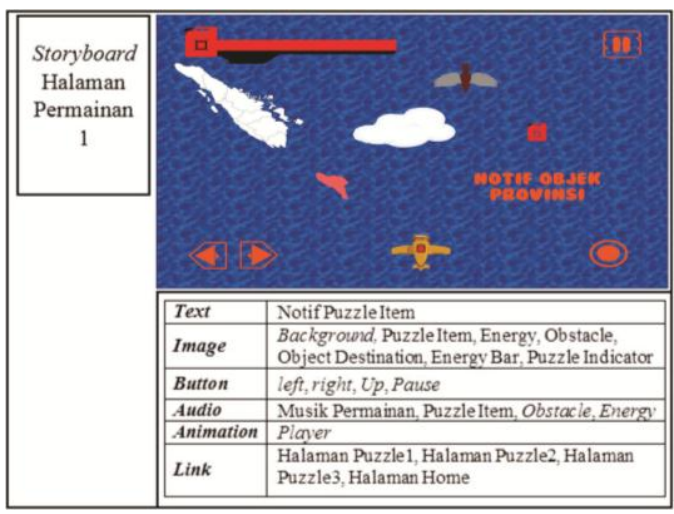

Gambar 7. Tampilan Storyboard Halaman Permainan1

Tampilan rancangan Permainan2 ditunjukkan pada Gambar 8. Tampilan halaman ini terdiri teks, gambar, audio, dan animasi. Selain itu terdapat tombol menu yang berisi panel pause yang digunakan untuk menghentikan permainan sementara juga terdapat panel yang berfungsi untuk menjawab pertanyaan dari salah satu bagian permainan dari halaman Permainan2

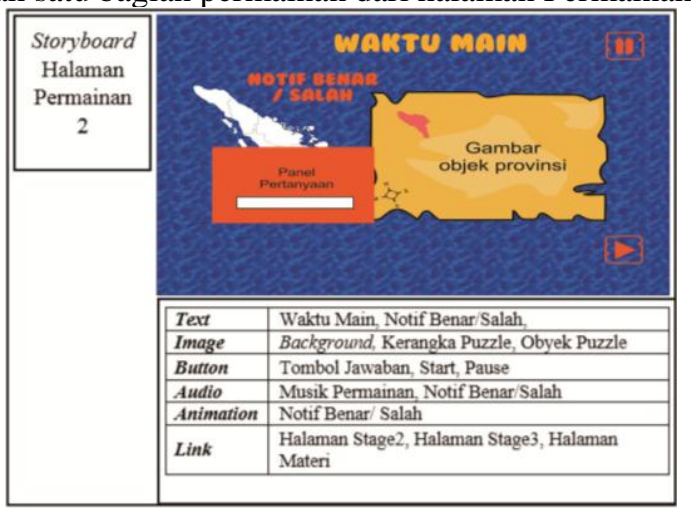

Gambar 8. Tampilan Storyboard Halaman Permainan2 
Masing-masing Storyboard memiliki hubungan dengan Storyboard yang lainnya. Berikut merupakan skema hubungan seluruh Storyboard yang ada dalam permainan yang ditunjukkan pada Gambar 9.

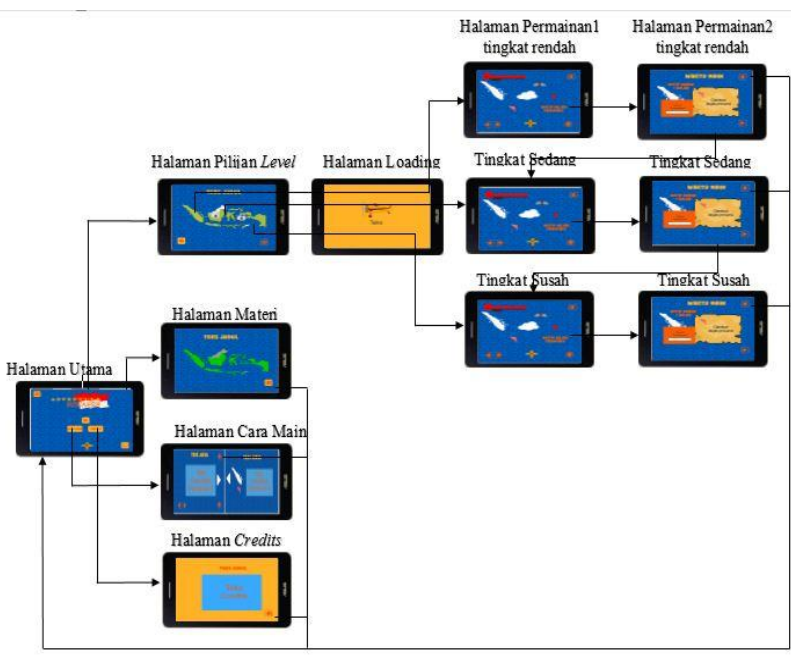

Gambar 9. Skema Hubungan antar Storyboard

\section{Pengumpulan Materi}

Pada tahap ini dilakukan pengumpulan materi dan konten-konten yang diperlukan dalam perancangan permainan Adventure Indonesia. Konten-konten yang diperlukan seperti tampilan grafik atau gambar-gambar dan efek suara yang telah dibuat sendiri untuk permainan ini. Untuk konten materi pada menu belajar diambil dari referensi buku IPS TERPADU untuk Sekolah Dasar Kelas VI karangan Tim Bina Karya Guru. Materi yang diambil kemudian disesuaikan kembali agar anak-anak dapat mencerna dengan baik materi tersebut.

\section{HASIL DAN PEMBAHASAN}

\section{A. Hasil Tampilan Aplikasi Permainan}

"Adventure Indonesia"

Aplikasi permainan "Adventure Indonesia" memiliki beberapa halaman yang digunakan yaitu halaman Utama, halaman Pemilihan Level, halaman Materi, halaman Tentang, halaman Loading, halaman Permainan1 dan halaman Permainan2. Setiap halaman memiliki sebuah Canvas yang berfungsi untuk menampilkan elemen gambar pada aplikasi. Canvas dapat membuat gambar dan elemen lainnya terlihat memiliki ukuran yang sama di semua resolusi smartphone.

Halaman utama akan muncul pada saat pertama kali aplikasi dijalankan. Tampilan halaman utama aplikasi ditunjukkan oleh Gambar 10.

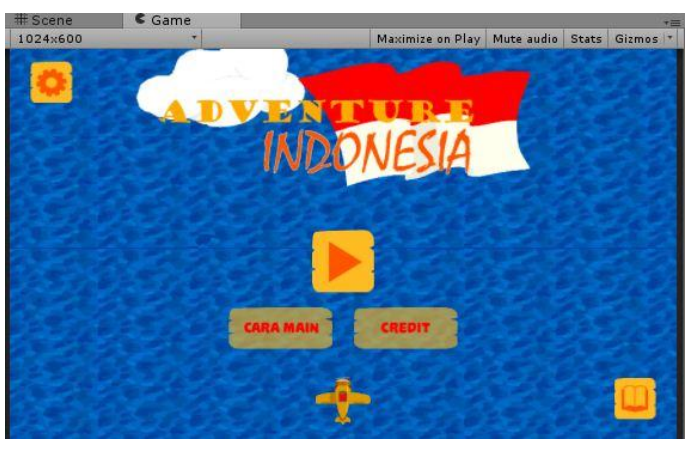

Gambar 10. Tampilan halaman utama

Halaman Pemilihan Level ditampilkan ketika tombol menu Mulai Permainan pada halaman utama ditekan.. Tampilan halaman Pemilihan Level ditunjukkan oleh Gambar 11.

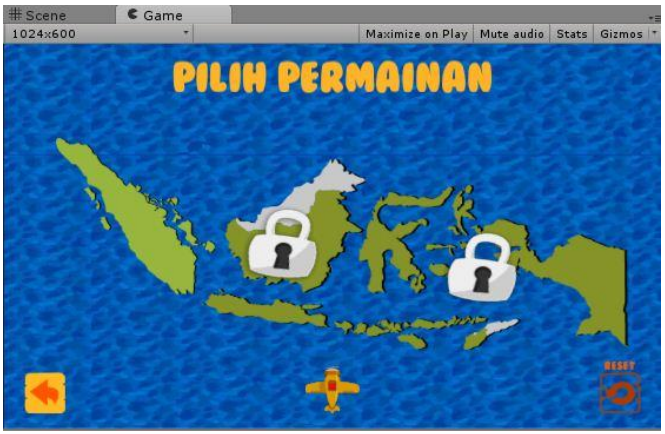

Gambar 11. Tampilan halaman Pemilihan Level

Halaman Materi berfungsi untuk memberikan informasi seputar provinsi yang ada di Indonesia. Tampilan halaman Materi ditunjukkan oleh Gambar 12.

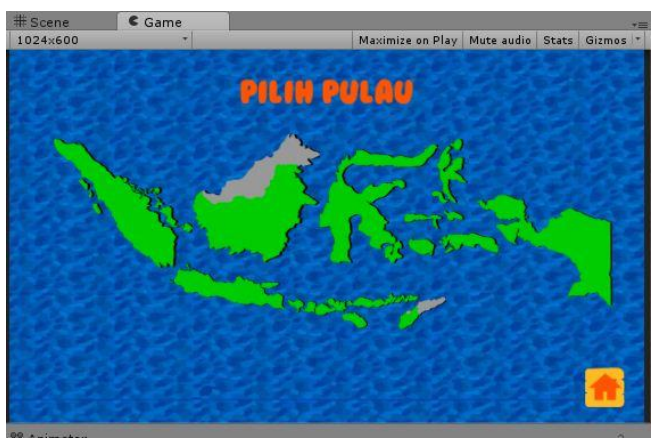

Gambar 12. Tampilan halaman Materi

Halaman Tentang akan menampilkan informasi tentang aplikasi permainan 'Adventure Indonesia'. 
Tampilan halaman Tentang ditunjukkan oleh Gambar 13.

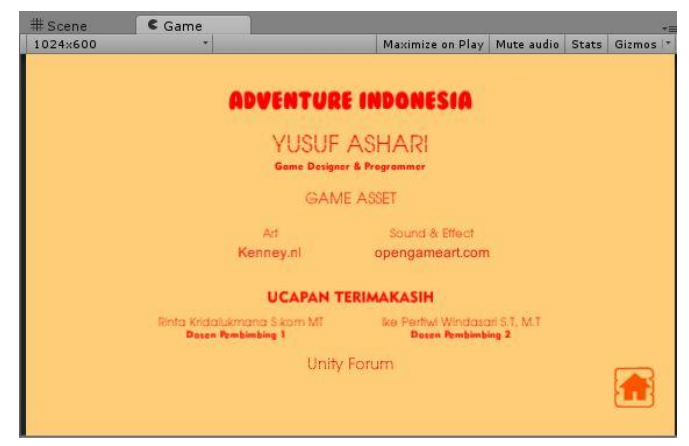

Gambar 13. Tampilan Halaman Tentang

Halaman Loading berfungsi untuk menampilkan misi utama permainan dan tips beserta fakta unik tentang kebersihan lingkungan. Tampilan halaman Loading ditunjukkan oleh Gambar 14.

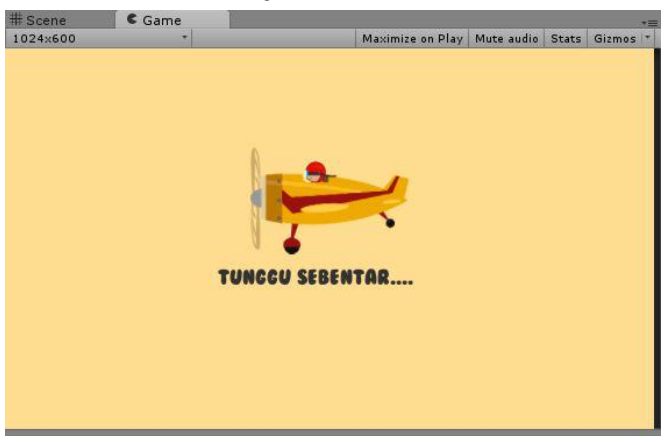

Gambar 14. Tampilan halaman Loading

Halaman permainan1 merupakan halaman dimana pemain dapat melakukan aksinya untuk menyelesaikan misi dari permainan pertama pada permainan ini. Tampilan halaman permainan1 ditunjukkan oleh Gambar 15. Tampilan ini juga digunakan pada permainan dengan tingkat sedang dan permainan tingkat susah.

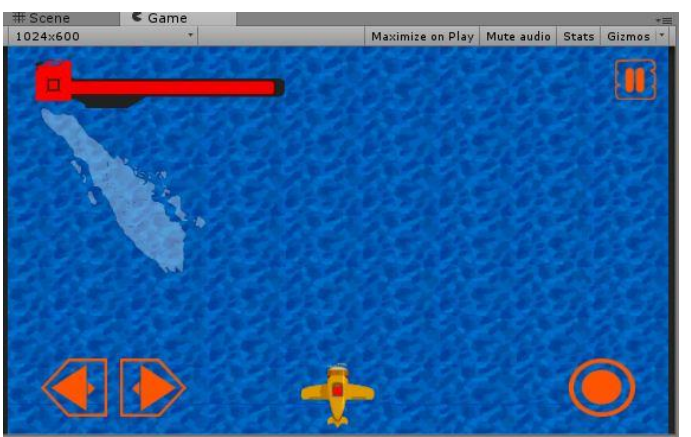

Gambar 15. Tampilan Halaman Permainan1

Halaman permainan2 merupakan halaman ditunjukkan dimana pemain dapat melakukan aksinya untuk menyelesaikan misi dari permainan kedua pada permainan ini Tampilan halaman permainan2 ditunjukkan oleh Gambar 16. Tampilan ini juga digunakan pada permainan dengan tingkat sedang dan permainan tingkat susah

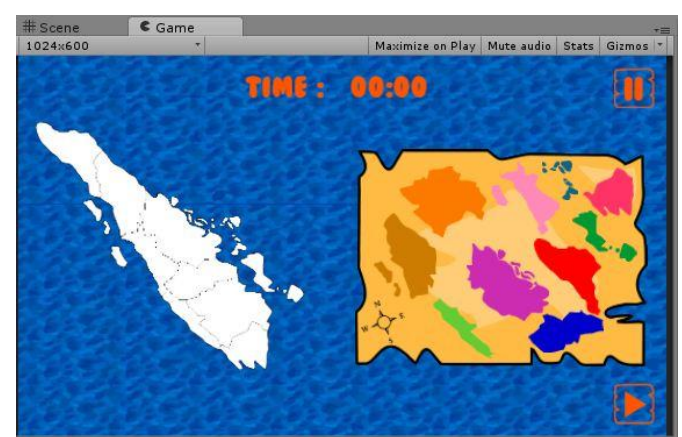

.Gambar 16. Tampilan Halaman Permainan 2

\section{B. Pengujian Aplikasi Menggunakan Metode Uji}

\section{Kotak Hitam}

Pengujian aplikasi permainan "Adventure Indonesia" ini dilakukan dengan menggunakan metode uji kotak hitam. Pengujian ini dilakukan untuk menunjukkan fungsi program yang dibuat tentang cara operasi dan kegunaannya, apakah keluaran data sesuai dengan yang diharapkan. Pengujian ini dilakukan untuk mengetahui apakah masih terjadi kesalahan program atau program sudah berhasil diselesaikan dengan benar. Berikut ini tabel pengujian pada halaman permainan1 yang ditunjukkan oleh Tabel 1.

TABEL 1.

TABEL PENGUJIAN HALAMAN PERMAINAN1

\begin{tabular}{|c|c|c|c|}
\hline $\begin{array}{c}\text { Nama } \\
\text { Pengujian }\end{array}$ & $\begin{array}{c}\text { Bentuk } \\
\text { Pengujian }\end{array}$ & $\begin{array}{c}\text { Hasil } \\
\text { yang Diharapkan }\end{array}$ & $\begin{array}{c}\text { Hasil } \\
\text { Pengujia } \\
\text { n }\end{array}$ \\
\hline $\begin{array}{l}\text { Pengujian } \\
\text { tombol } \\
\text { 'maju' }\end{array}$ & $\begin{array}{l}\text { Klik dan } \\
\text { tahan tombol } \\
\text { 'maju' }\end{array}$ & $\begin{array}{l}\text { Pemain berjalan } \\
\text { maju }\end{array}$ & Berhasil \\
\hline $\begin{array}{l}\text { Pengujian } \\
\text { tombol } \\
\text { 'kanan' }\end{array}$ & $\begin{array}{l}\text { Klik dan } \\
\text { tahan tombol } \\
\text { 'kanan' }\end{array}$ & $\begin{array}{l}\text { Pemain berjalan ke } \\
\text { kanan }\end{array}$ & Berhasil \\
\hline $\begin{array}{l}\text { Pengujian } \\
\text { tombol 'kiri' }\end{array}$ & $\begin{array}{l}\text { Klik dan } \\
\text { tahan tombol } \\
\text { 'kiri' }\end{array}$ & $\begin{array}{l}\text { Pemain berjalan ke } \\
\text { kiri }\end{array}$ & Berhasil \\
\hline $\begin{array}{l}\text { Pengujian } \\
\text { cek sisa } \\
\text { energi }\end{array}$ & $\begin{array}{l}\text { Mengecek } \\
\text { sisa energi }\end{array}$ & $\begin{array}{l}\text { Bila energi > } 0 \\
\text { aktor terus berjalan } \\
\text { dan jarak yang } \\
\text { ditempuh } \\
\text { bertambah. Bila } \\
\text { energi }<=0 \text { pemain } \\
\text { berhenti }\end{array}$ & Berhasil \\
\hline $\begin{array}{l}\text { Pengujian } \\
\text { tambah } \\
\text { energi }\end{array}$ & $\begin{array}{l}\text { Aktor } \\
\text { pesawat } \\
\text { menyentuh } \\
\text { objek bensin }\end{array}$ & $\begin{array}{l}\text { Aktor pesawat } \\
\text { menyentuh bensin, } \\
\text { bensin hilang } \\
\text { energi bar } \\
\text { bertambah. }\end{array}$ & Berhasil \\
\hline $\begin{array}{l}\text { Pengujian } \\
\text { sentuh } \\
\text { penghalang } \\
\text { awan }\end{array}$ & $\begin{array}{l}\text { Aktor } \\
\text { pesawat } \\
\text { menyentuh } \\
\text { objek awan }\end{array}$ & $\begin{array}{l}\text { Aktor pesawat } \\
\text { menyentuh awan, } \\
\text { aktor pesawat } \\
\text { berjalan pelan dan } \\
\text { energi bar } \\
\text { berkurang }\end{array}$ & Berhasil \\
\hline $\begin{array}{l}\text { Pengujian } \\
\text { sentuh } \\
\text { penghalang } \\
\text { burung }\end{array}$ & $\begin{array}{l}\text { Aktor } \\
\text { pesawat } \\
\text { menyentuh } \\
\text { objek } \\
\text { burung }\end{array}$ & $\begin{array}{l}\text { Aktor pesawat } \\
\text { menyentuh burung, } \\
\text { animasi burung } \\
\text { jatuh, energi bar } \\
\text { berkurang. }\end{array}$ & Berhasil \\
\hline $\begin{array}{l}\text { Pengujian } \\
\text { sentuh objek } \\
\text { provinsi }\end{array}$ & $\begin{array}{l}\text { Aktor } \\
\text { pesawat } \\
\text { menyentuh }\end{array}$ & $\begin{array}{l}\text { Aktor pesawat } \\
\text { akan menyentuh } \\
\text { objek provinsi. } \\
\text { Provinsi hilang. }\end{array}$ & Berhasil \\
\hline
\end{tabular}

JTsiskom - 394 


\begin{tabular}{|l|l|l|l|}
\hline & $\begin{array}{l}\text { objek } \\
\text { provinsi }\end{array}$ & $\begin{array}{l}\text { Keluar notifikasi } \\
\text { ibukota provinsi, } \\
\text { objek provinsi } \\
\text { yang dikumpulkan } \\
\text { akan mucul pada } \\
\text { indikator pulau. }\end{array}$ & \\
\hline $\begin{array}{l}\text { Pengujian } \\
\text { misi } \\
\text { permainan } \\
\text { sukses }\end{array}$ & $\begin{array}{l}\text { Aktor } \\
\text { pesawat } \\
\text { berhasil } \\
\text { mengumpulk } \\
\text { an objek } \\
\text { provinsi }\end{array}$ & $\begin{array}{l}\text { Aktor pesawat } \\
\text { selesai } \\
\text { mengumpulkan } \\
\text { objek provinsi, } \\
\text { keluar objek pulau } \\
\text { sebagai destinasi, } \\
\text { aktor menyentuh } \\
\text { pulau dan keluar } \\
\text { panel sukses. }\end{array}$ & Berhasil \\
\hline $\begin{array}{l}\text { Pengujian } \\
\text { energi Bar } \\
\text { habis di } \\
\text { halaman } \\
\text { permainan } \\
\text { tingkat } \\
\text { mudah. }\end{array}$ & $\begin{array}{l}\text { Aktor } \\
\text { pesawat } \\
\text { melaju } \\
\text { sampai } \\
\text { energi bar } \\
\text { berwarna } \\
\text { merah } \\
\text { (habis) }\end{array}$ & $\begin{array}{l}\text { Tokoh pemain } \\
\text { akan berhenti dan } \\
\text { akan menampilkan } \\
\text { panel Game Over. }\end{array}$ & Berhasil \\
\hline $\begin{array}{l}\text { Pengujian } \\
\text { tombol'paus } \\
e \text { ' }\end{array}$ & $\begin{array}{l}\text { Klik tombol } \\
\text { 'pause' }\end{array}$ & $\begin{array}{l}\text { Permainan } \\
\text { berhenti, tampil } \\
\text { panel pause }\end{array}$ & Berhasil \\
\hline $\begin{array}{l}\text { Pengujian } \\
\text { 'mambol } \\
\text { pause }\end{array}$ & $\begin{array}{l}\text { Klik tombol } \\
\text { 'resume' } \\
\text { panel pause }\end{array}$ & $\begin{array}{l}\text { Tampil penghitung } \\
\text { mundur, bila } \\
\text { penghitung } \\
\text { mundur selesai } \\
\text { Permainan } \\
\text { dilanjutkan }\end{array}$ & Berhasil \\
\hline $\begin{array}{l}\text { Pengujian } \\
\text { 'keluar' }\end{array}$ & $\begin{array}{l}\text { Tampil halaman } \\
\text { utama }\end{array}$ & Berhasil \\
\hline
\end{tabular}

Berikut ini merupakan tabel pengujian pada halaman permainan 2 yang ditunjukkan oleh tabel 2 . TABEL 2.

TABEL PENGUJIAN HALAMAN PERMAINAN2

\begin{tabular}{|l|l|l|c|}
\hline \multicolumn{1}{|c|}{$\begin{array}{c}\text { Nama } \\
\text { Pengujian }\end{array}$} & \multicolumn{1}{|c|}{$\begin{array}{c}\text { Bentuk } \\
\text { Pengujian }\end{array}$} & $\begin{array}{l}\text { Hasil yang } \\
\text { Diharapkan }\end{array}$ & $\begin{array}{c}\text { Hasil } \\
\text { Pengujian }\end{array}$ \\
\hline $\begin{array}{l}\text { Pengujian } \\
\text { tombol }\end{array}$ & $\begin{array}{l}\text { Klik tombol } \\
\text { 'start' }\end{array}$ & $\begin{array}{l}\text { Permainan } \\
\text { bisa dimulai } \\
\text { dan waktu } \\
\text { berjalan } \\
\text { mundur }\end{array}$ & Berhasil \\
\hline $\begin{array}{l}\text { Pengujian } \\
\text { tombol } \\
\text { 'pause' }\end{array}$ & $\begin{array}{l}\text { Klik tombol } \\
\text { 'pause' }\end{array}$ & $\begin{array}{l}\text { Permainan } \\
\text { berhenti, } \\
\text { tampil panel } \\
\text { pause. }\end{array}$ & Berhasil \\
\hline $\begin{array}{l}\text { Pengujian } \\
\text { tombol 'main' } \\
\text { panel pause }\end{array}$ & $\begin{array}{l}\text { Klik tombol } \\
\text { 'resume' } \\
\text { panel pause }\end{array}$ & $\begin{array}{l}\text { Pemain } \\
\text { berjalan } \\
\text { kembali }\end{array}$ & Berhasil \\
\hline $\begin{array}{l}\text { Pengujian } \\
\text { tombol } \\
\text { 'keluar' panel } \\
\text { pause }\end{array}$ & $\begin{array}{l}\text { Klik tombol } \\
\text { 'keluar' panel } \\
\text { pause }\end{array}$ & $\begin{array}{l}\text { Tampil } \\
\text { halaman } \\
\text { utama }\end{array}$ & Berhasil \\
\hline $\begin{array}{l}\text { Pengujian } \\
\text { waktu habis di } \\
\text { halaman } \\
\text { permainan2 }\end{array}$ & $\begin{array}{l}\text { Waktu di } \\
\text { halaman } \\
\text { permainan } \\
\text { menunjukkan } \\
\text { angka } \\
\text { 00:00:00 }\end{array}$ & $\begin{array}{l}\text { Permainan } \\
\text { akan berhenti } \\
\text { dan akan } \\
\text { muncul panel } \\
\text { game over }\end{array}$ & Berhasil \\
\hline $\begin{array}{l}\text { Pengujian } \\
\text { menyusun } \\
\text { objek provinsi } \\
\text { ke dalam } \\
\text { objek } \\
\text { kerangka } \\
\text { pulau }\end{array}$ & $\begin{array}{l}\text { Pemain meng } \\
\text { drag objek } \\
\text { provinsi dan } \\
\text { kemudian meng } \\
\text { drop kan ke } \\
\text { dalam } \\
\text { objekkerangka } \\
\text { pulau }\end{array}$ & $\begin{array}{l}\text { Akan muncul } \\
\text { panel } \\
\text { pertanyaan } \\
\text { yang harus } \\
\text { dijawab oleh } \\
\text { permain agar } \\
\text { bisa } \\
\text { menyusun }\end{array}$ & Behasil \\
\hline
\end{tabular}

\begin{tabular}{|c|c|c|c|}
\hline & & $\begin{array}{l}\text { objek yang } \\
\text { lain }\end{array}$ & \\
\hline \begin{tabular}{ll|}
\multicolumn{2}{|l|}{ Pengujian } \\
menjawab soal \\
dari panel \\
dengan benar
\end{tabular} & $\begin{array}{l}\text { Pemain } \\
\text { menjawab } \\
\text { dengan jawaban } \\
\text { yang benar }\end{array}$ & $\begin{array}{l}\text { Muncul } \\
\text { animasi } \\
\text { notifikasi } \\
\text { jawaban } \\
\text { benar dan } \\
\text { objek } \\
\text { provinsi } \\
\text { berada di } \\
\text { posisi } \\
\text { terpasang di } \\
\text { objek pulau. }\end{array}$ & Berhasil \\
\hline $\begin{array}{l}\text { Pengujian } \\
\text { menjawab soal } \\
\text { dari panel } \\
\text { dengan salah }\end{array}$ & $\begin{array}{l}\text { Pemain } \\
\text { menjawab } \\
\text { dengan jawaban } \\
\text { yang salah }\end{array}$ & $\begin{array}{l}\text { Muncul } \\
\text { animasi } \\
\text { notifikasi } \\
\text { jawaban } \\
\text { salah dan } \\
\text { objek } \\
\text { provinsi } \\
\text { kembali ke } \\
\text { posisi awal. }\end{array}$ & Berhasil \\
\hline $\begin{array}{l}\text { Pengujian } \\
\text { menyelesaikan } \\
\text { permainan2 }\end{array}$ & $\begin{array}{l}\text { Pemain berhasil } \\
\text { menyusun } \\
\text { objek provinsi } \\
\text { dan menjawab } \\
\text { semua } \\
\text { pertanyaan yang } \\
\text { ada }\end{array}$ & $\begin{array}{l}\text { Permainan } \\
\text { akan berhenti } \\
\text { dan akan } \\
\text { muncul panel } \\
\text { game sukses. }\end{array}$ & Berhasil \\
\hline
\end{tabular}

\section{Distribusi}

Hasil aplikasi permainan dapat didistribusikan ke perangkat dengan system operasi Android pengguna melalui Android SDK yang terintegrasi dengan Unity. Selain itu pendistribusian permainan ini juga dilakukan dengan mem-publish permainan tersebut ke Playstore. Tujuan dari pendistribusian permainan ini selain untuk menyebarkan permainan melalui jaringan juga untuk dapat menjadi sebuah evaluasi sehingga akan dapat mengembangkan sistem menjadi lebih baik lagi.

\section{KESIMPULAN DAN SARAN}

\section{A. Kesimpulan}

Kesimpulan dari penelitian tugas akhir ini diantaranya sebagai berikut.

1. Aplikasi permainan 'Adventure Indonesia' telah berhasil dirancang dan dibangun menggunakan Unity kemudian diekspor ke dalam bentuk ekstensi file .apk.

2. Penyajian materi di dalam aplikasi permainan yang menjelaskan peta disetiap provinsi di Indonesia telah berhasil dan berjalan sesuai dengan fungsinya masing-masing.

3. Fungsi permainan dengan tujuan agar pengguna dapat mengenali peta provinsi dan ibukota setiap provinsi di Indonesia telah berhasil dan berjalan sesuai dengan fungsinya masing-masing..

4. Berdasarkan hasil pengujian permainan menggunakan black-box testing, seluruh fungsi menu yang ada dalam aplikasi permainan telah berhasil dan berjalan sesuai dengan fungsinya masing-masing.

\section{B. Saran}


Saran yang dapat diberikan oleh penulis adalah sebagai berikut.

1. Elemen yang digunakan pada permainan Adventure Indonesia seperti Karakter Pesawat, pulau, dan penghalang dapat ditambahkan lagi sehingga lebih bervariasi.

2. Tingkat permainan perlu ditambah lagi, misal pada setiap pulau / kepulauan dibuat tingkatan permainan sendiri agar permainan tidak terkesan monoton.

3. Penambahan animasi yang lebih atraktif dan menarik.

4. Permainan dapat dijalankan disistem operasi lain seperti Windows phone dan iOS agar penyebarannya lebih luas

\section{DAFTAR PUSTAKA}

[1] Sunarto, A. Umar, Suparna and dkk, IPS TERPADU untuk Sekolah Dasar Kelas VI, Jakarta: Erlangga, 2015.

[2] A. R. Jordiawan, "PERANCANGAN BOARD GAME SEBAGAI MEDIA PEMBELAJARAN ILMU PENGETAHUAN SOSIAL UNTUK MENGENALKAN 34 PROVINSI INDONESIA BAGI SISWA SEKOLAH DASAR," Universitas Telkom, Bandung, 2015.
[3] R. e. a. Setyaningsih, "Game Matematika Untuk Pembelajaran Murid SD," Makalah Proyek Akhir, 2010.

[4] V. Anggiawan, David and A. A. Tandiputra, Perancangan Game Edukasi Peta Buta Indonesia Untuk Siswa Sekolah Dasar Katolik Abdi Siswa Berbasis Multimedia, Jakarta: BINA NUSANTARA UNIVERSITY, 2011.

[5] F. A. Arnami, "Analisis dan Perancangan Aplikasi Game Novel Interaktif Takdir Mudaku Berbasis Android," Jurusan Informatika STIMIK AMIKOM, Yogyakarta, 2013.

[6] H. M. C. a. R. Chandler, Fundamentals of Game Development, LLC: Jones \& Barlett Learning, 2011.

[7] F. Ardiansyah, Pengenalan Dasar Android Programming, Depok: Biraynara Copyrigh, 2011.

[8] M. Suryanto, Multimedia : Alat untuk Meningkatkan Keunggulan Bersaing, Yogyakarta: ANDI, 2009.

[9] I. Binanto, Multimedia Digital: Dasar Teori dan Pengembangannya, Yogyakarta: ANDI, 2010.

[10] A. H. Sutopo, Multimedia Interaktif Dengan Flash, Yogyakarta: Graha Ilmu, 2003.

[11] R. H. Creighton, Unity 3D Game Development by Example, Birmingham: Packt Publishing, 2010. 
